\title{
Biofiltration of Gaseous Toluene Using Activated Carbon Containing Polyurethane Foam Media
}

\author{
Altangerel Amarsanaa, Won-Sik Shin, Jeong-Hak Choi and Sang-June Choi \\ Department of Environmental Engineering, Kyungpook National University, Daegu 702-701, Korea \\ "Environment Research Department, Research Institute of Industrial Science \& Technology, Kyungbuk 790-330, Korea \\ (Manuscript received 8 February, 2005; accepted 18 May, 2006)
}

In recent decades, biofiltration has been widely accepted for the treatment of contaminated air stream containing low concentration of odorous compounds or volatile organic compounds (VOCs). In this study, conventional biofilters packed with flexible synthetic polyurethane (PU) foam carriers were operated to remove toluene from a contaminated air stream. PU foams containing various amounts of pulverized activated carbon (PAC) were synthesized for the biofilter media and tested for toluene removal. Four biofilter columns were operated for 60 days to remove gaseous toluene from a contaminated air stream. During the biofiltration experiment, inlet toluene concentration was in the range of $0-150 \mathrm{ppm}$ and EBRT (i.e., empty bed residence time) was kept at 26-42 seconds. Pressure drop of the biofilter bed was less than $3 \mathrm{~mm} \mathrm{H} 2 \mathrm{O} / \mathrm{m}$ filter bed. The maximum removal capacity of toluene in the biofilters packed with PU-PAC foam was in the order of column II (PAC $=7.08 \%)>$ column III $(\mathrm{PAC}=8.97 \%)>$ column I $(\mathrm{PAC}=4.95 \%)>$ column IV $(\mathrm{PAC}=13.52 \%)$, while the complete removal capacity was in the order of column II $>$ column I $>$ column III $>$ column IV. The better biofiltration performance in column II was attributed to higher porosity providing favorable conditions for microbial growth. The results of biodegradation kinetic analysis showed that PU-PAC foam with $7.08 \%$ of PAC content had higher maximum removal rate $\left(V_{\mathrm{m}}=14.99 \mathrm{~g}\right.$ toluene $/ \mathrm{kg}$ dry material/day) than the other PU-PAC foams. In overall, the performance of biofiltration might be affected by the structure and physicochemical properties of PU foam induced by PAC content.

Key Words : Biodegradation kinetics, Biofiltration, Powered activated carbon (PAC), Polyurethane foam, Toluene

\section{Introduction}

Biofiltration technology has a promising potential as aneffective and economical treatment technology than the traditional treatment technologies for treating contaminated air stream with low concentration of odorous compounds and/or volatile organic compounds (VOCs). The fundamental principle of biofiltration of polluted air is that gaseous pollutants are destroyed in the process being converted into carbon dioxide, water and biomass by microbial metabolic reactions. During the biofiltration, polluted air is passed through the biofilter medium where the pollu-

Corresponding Author : Won-Sik Shin, Department of Environmental Engineering, Kyungpook National University, Daegu 702-701, Korea

Phone: +82-53-950-7584

E-mail: wshin@mail.knu.ac.kr tant is transferred from the gas to the liquid-solid phase where they are degraded by biofilm ${ }^{1 \sim 3)}$.

The concept of biofiltration to treat waste gases is similar to other forms of biological wastewater treatment. In biofiltration, a fan or blower forces gases containing biodegradable VOCs through a packed bed that contains an unsaturated solid medium that supports a biologically active aqueous layer. As contaminated air flows through the support medium and past the aqueous biofilm, contaminants partition to the aqueous or solid phases where they are transformed by microorganisms into inert products such as carbon dioxide, water, and biosolids.

Biofiltration primarily depends on the choice of the packing material. A proper packing material should have favorable conditions such as high porosity, ap- 
propriate pore size and suitable surface area for $\mathrm{mi}-$ crobial growth and lower clogging effect that involves biofilter systems operated for long periods of time $e^{2-4)}$.

While packing media used in conventional biofilter beds consist mostly of peat or compost, a wide variety of other materials have been used. These include soil, wood chips, bark, sawdust, activated carbon, ceramic, ground tires, polystyrene beads and polyurethane foam ${ }^{4 \sim 7,23,24)}$. In addition to the primary support medium, a variety of additives may be used including bulking agents, buffers, nutrients, and microorganisms ${ }^{8}$.

High porosity, appropriate pore size, low density, and the ability to sorb water are features important to the proper operation of packed bed biofilters. High porosity permits the uniform gas flow distribution needed for maximum contact between the gas stream contaminants and the microbial population. Pore size is directly related to head loss and clogging problems that often result from microbial growth. Low density, an obvious advantage in construction, helps minimize compaction of the bed due to the weight of the packing material itself $f^{9)}$. Because microorganisms grow best on wet surfaces, the ability of filter material to absorb water is also an important factor in medium selection. In spite of their increasing popularity, three problems are commonly cited for conventionally designed and operated biofilter systems. The first, clogging due to excessive microbial growth in overloaded systems or systems operated for long periods of time under normal loading. The second, inadequate moisture control, results in decreased biofilter performance. The third, nutrient content of filter beds, is sometimes difficult to control. Several methods have been developed to alleviate the problem of biofilter clogging. Sorial et al. developed a successful backwashing procedure for biofilters packed with ceramic pellets but the daily downtime was appreciable and full-bed fluidization was required ${ }^{10}$. Holubar et al. controlled clogging by limiting the addition of nutrients at the expense of biofilter performance ${ }^{(1)}$. They also tested terminating contaminant flow and extending periods of endogenous respiration but found that several weeks of aeration were not sufficient to unclog the biofilter. Farmer et al. investigated a system of three biofilters in series where the lead biofilter receiving contaminated inflow was periodically operated ${ }^{(2)}$. Although this decreased net biomass production in biofilters not in the lead position, clogging was still a problem. Severin et al. sparged air and water through a biofilter and successfully dislodged excess biosolids ${ }^{13)}$.

Proper control of moisture content is also critical to biofilter performance. Some biofilter support materials, including peat and compost, are hydrophobic when clry and are not easily re-wetted ${ }^{13,18,23,24)}$ while others, such as polyurethane foam, are produced from hydrophilic materials that are easily re-wetted ${ }^{4 \sim 7,15)}$. While an optimum range of moisture content can be determined experimentally for each material, moisture content is difficult to maintain in practice. For example, direct application of water may result in flooded zones, and humidification of the influent air is inadequate if microbially induced temperature rise reduce the air's relative humidity to less than $100 \%$.

Nutrient limitations can have a negative impact on contaminant removal ${ }^{4,13,14)}$. In many applications, nutrients are added to biofilters either with the packing material before biofilter assembly or in a nutrient solution sprayed on or mixed with the packing material after construction ${ }^{8)}$. Because nutrients are added in aqueous solution, simultaneous control of moisture and nutrient levels is difficult when using most conventional packing materials. A medium such as polyurethane foam allows nutrients to be adjusted independently from moisture content.

m.In order to overcome limitations associated with conventional biofilter design and operation, experiments were conducted to examine a new biofilter medium, polyurethane foam. Moe et al. used digital image analysis to study pore size distribution in the foam and found that homogenous polyurethane foam could be made in the laboratory with porosity and surface area that compares favorably to materials traditionally used in packed bed reactors ${ }^{14)}$. The new medium also permits use of novel nutrient addition and biosolids wasting strategies.

The chemistry of polyurethane formulation uses the reaction of organic isocyanates with compounds containing active hydrogen atoms such as polyols or polyamines. Generally, choice of the starting molecules of polyurethane foam highly affects the phys- 
icochemical properties of foam ${ }^{4,15,16)}$. In addition, polyurethane foam may also be made from hydrophilic and sorption materials that are easily rewetted if drying occur. As a general rule, any additive such as adsorbents that can be present in the water (in solution, suspended, emulsified, etc.) can be incorporated into an aqueous phase and become an integral part of polyurethane foam through covalent bonding or physical entrapment ${ }^{16)}$.

Packing material used in biofilter beds can be broadly categorized as either natural or synthetic. Natural media include peat, soil, compost, back, wood chips; synthetic media that have been used, which include activated carbon, ceramic, sintered glass, polystyrene beads and polyurethane foam ${ }^{2 \sim 4}$. A good media can be incorporated several or all of the desirable properties; these include high porosity, appropriate pore size, low density and an ability to sorb water ${ }^{2 \sim 4)}$.

In this study, conventional biofilters using polyurethane foams as packing material were operated for the removal of toluene from air stream. Polyurethane foams containing various amounts of PAC were synthesized as biofilter media. The effects of various PAC contents adsorbents on the biofiltration of gaseous toluene were investigated. The biodegradation kinetics of these systems was also analyzed.

\section{Materials and Methods}

\subsection{Synthesis of PU-PAC Foam}

Polyurethane (PU) foam used in this study was made from Hypol 3000 prepolymer (Dow Chemical Co., Midland, MI, USA). The nonionic surfactant, Tween 85 was obtained from Aldrich Chemical Co. (Milwakee, WI, USA) and PAC was obtained from Duksan Pure Chemicals Co., Ltd. (Ansan, Korea).

PU foam was synthesized by slight modification of the procedure previously reported by Moe et al. 15) Surfactant solutions, ranging from 2 to $40 \mathrm{~g} / \mathrm{L}$, were prepared by dissolving Tween 85 surfactant in deionized water (DI water, resistivity $\geq 17.5 \mathrm{M} \Omega \cdot \mathrm{cm}$ ) and cooling to $4^{\circ} \mathrm{C}$. To manufacture polyurethane foam, Hypol 3000 prepolymer was heated to $55^{\circ} \mathrm{C}$ in a water bath and maintained at that temperature for at least $2 \mathrm{~h}$ before being combined with surfactant solution. Approximately $110 \mathrm{~g}$ of Hypol 3000 and $110 \mathrm{~g}$ of surfactant solution were added into a
Teflon beaker (Nalgene, USA), vigorously mixed for 20 seconds using a plastic spoon, and then poured into a cylindrical cardboard mold $(8.5 \mathrm{~cm}$ i.d. $\times 12$ $\mathrm{cm}$ long). As the foaming reaction progressed, polyurethane foam expanded to fill the mold. The foam was air dried before the mold was removed. Before further testing, the impermeable "skin" that formed on the outermost layer of the foam (and adhered to the cardboard mold) was removed as were the top and bottom $1 \mathrm{~cm}$ of each cylinder. Free surfactant was rinsed from the foam by repeatedly washing with DI water.

The procedure used to make an adsorbent containing polyurethane foam composite material was the same as that for manufacturing foam without adsorbent except that prior to adding the surfactant solution to the Hypol 3000, adsorbent was mixed into the surfactant solution $(30 \mathrm{~g} / \mathrm{L}$ of Tween 85 in deionized water cooled to $8^{\circ} \mathrm{C}$ ) by stirring vigorously with a plastic spoon for approximately 10 seconds until no adsorbent floated on the surface. The adsorbents were sieved by U.S. Mesh No. 250-350 prior to use. The resulting foam cylinders were repeatedly rinsed with distilled water by submerging in a plastic bucket containing $2 \mathrm{~L}$ of DI water and repeatedly squeezing (approximately 10 times). Excess water in the rinsed foams was squeezed completely, and then the foams were rinsed in a new 2 L of DI water. This rinsing process was repeated by five times. After the rinsing process the foam cylinders were dried in an oven at $60^{\circ} \mathrm{C}$ for several days, and then the dried foams were placed in $1 \mathrm{~L}$ of glass jars filled with DI water. The water was allowed to sit for $24 \mathrm{~h}$, drained and then refilled. This process was repeated for 10 times to remove surfactant.

The density of dry foam and wet foam $(65 \%$ moisture content) was calculated by dividing the mass of the foam by the volume of the foam. Percent swelling in the horizontal direction and vertical direction was calculated by dividing the difference between wet dimensions and dry dimensions by the dry dimensions and multiplying by $100 \%$. The void space in the PU-adsorbent foam was measured using water displacement. The physicochemical properties of the synthesized PU-adsorbent foams were summarized in Table 1. 
Altangerel Amarsanaa, Won-Sik Shin, Jeong-Hak Choi and Sang-June Choi

Table 1. Physicochemical properties of PU-PAC foams used

\begin{tabular}{|c|c|c|c|c|}
\hline Properties & Foam I & Foam I & Foam III & Foam IV \\
\hline Final PAC content (\%) & 4.95 & 7.08 & 8.97 & 13.52 \\
\hline Dry density $\left(\mathrm{kg} / \mathrm{m}^{3}\right)$ & 94.0 & 96.0 & 99.0 & 108.0 \\
\hline Density at $65 \%$ moisture content $\left(\mathrm{kg} / \mathrm{m}^{3}\right)$ & 132.0 & 136.0 & 142.0 & 151.0 \\
\hline $\begin{array}{l}\text { Swelling in vertical direction } \\
\text { at } 65 \% \text { moisture content }\end{array}$ & 36.92 & 29.75 & 31.54 & 28.28 \\
\hline $\begin{array}{l}\text { Swelling in horizontal direction } \\
\text { at } 65 \% \text { moisture content }\end{array}$ & 21.93 & 24.62 & 23.21 & 24.30 \\
\hline $\begin{array}{l}\text { Swelling in volume } \\
\text { at } 65 \% \text { moisture content }\end{array}$ & 103.76 & 106.01 & 99.71 & 105.60 \\
\hline Porosity at $65 \%$ moisture content & 0.77 & 0.82 & 0.77 & 0.78 \\
\hline
\end{tabular}

\subsection{Experimental Apparatus}

Figure 1 shows a schematic diagram of biofilter used for toluene removal experiment. Each glass column $(8.5 \mathrm{~cm}$ i.d. $\times 50 \mathrm{~cm}$ long $)$ was filled with three cylindrical pieces of flexible synthetic PU foam (i.e., 3 $\times 10.1 \mathrm{~cm}$ height) to provide a total bed depth of approximately $30.3 \mathrm{~cm}$ and a total bed volume of approximately $1.7 \mathrm{~L}$. The column I, II, III, and IV were packed with PU foam cylinders $\mathrm{A}, \mathrm{B}, \mathrm{C}$, and $\mathrm{D}$ containing $4.95 \%, 7.08 \%, 8.97 \%$ and $13.52 \%$ of $\mathrm{PAC}$ by mass, respectively (Table 1). Initial operating conditions of biofiltration process were summarized in Table 2.

Compressed air flowed through Masterflex ${ }^{\otimes}$ Norprene tubing (Cole-Parmer, Vernon Hills, IL, USA) to prevent undesired contaminations. Toluene (Aldrich Chemical Co., USA) was delivered into the column by a syringe pump (KD Scientific, Model 100, Boston, MA, USA). Aqueous toluene in a glass gas-tight syringe (Hamilton Co, Reno, NV, USA) was injected through a 32 gauge stainless steel needle (Hamilton Co, Reno, NV, USA) into the air stream. A pressure regulator was used to adjust the air pressure to approximately $10 \mathrm{psi}$. The airflow (total contaminated air stream) rates were measured and regulated by flowmeters (Gilmont Instruments, $150 \mathrm{~mm}$ scale Accucal flowmeters). All surfaces that contacted contaminated air were made of glass, stainless steel, Teflon ${ }^{\mathrm{TM}}$ or Viton ${ }^{\mathrm{TM}}$.

2.3. Fixed Bed Adsorption Experiment

Fixed bed adsorption of toluene on PU foam me-

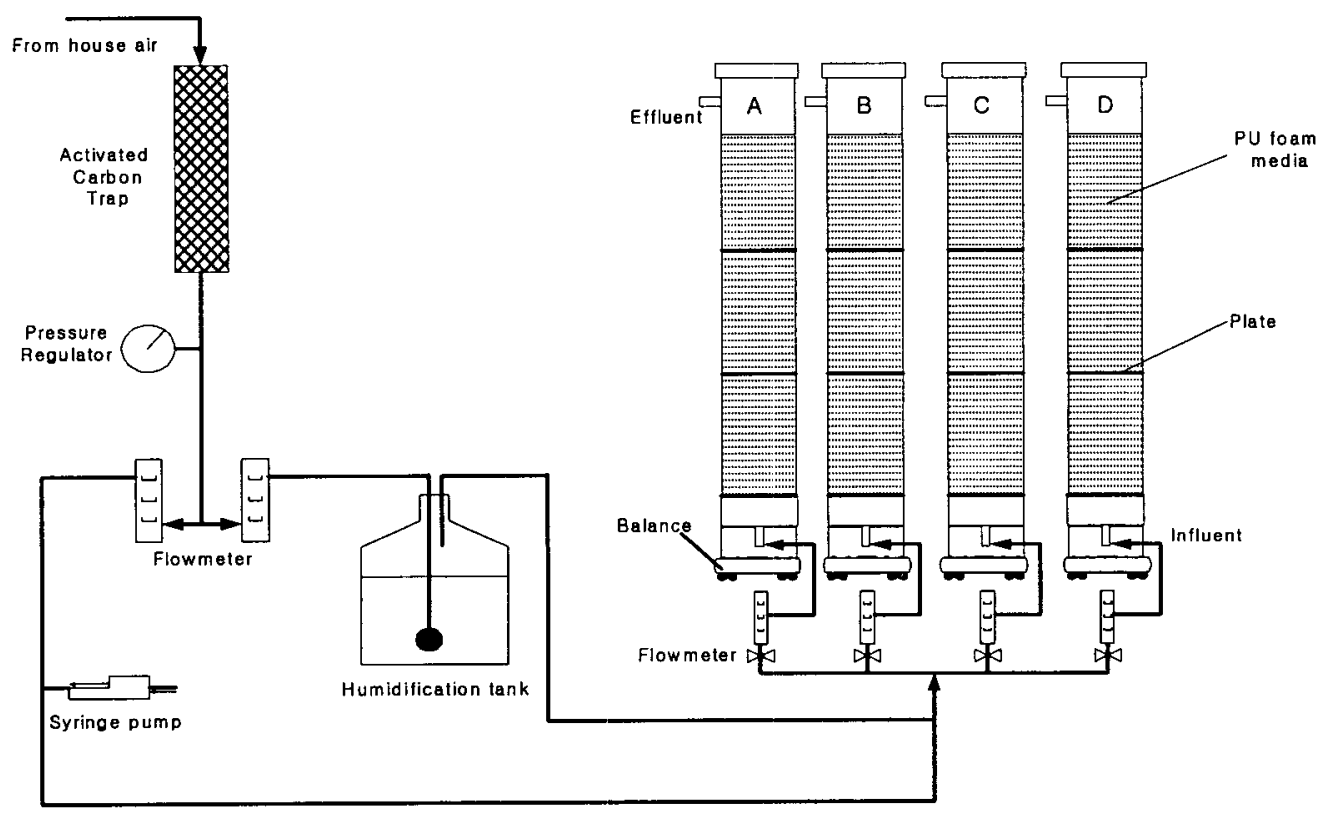

Fig. 1. Schematic diagram of laboratory biofilter system. 
Table 2. Initial operating conditions of biofiltration

\begin{tabular}{|c|c|c|c|c|}
\hline & \multicolumn{4}{|c|}{ Polyurethane foams containing PAC } \\
\hline & Column I & Column II & Column III & Column IV \\
\hline PAC content $(\%)$ & 4.95 & 7.09 & 8.97 & 13.52 \\
\hline Packing weight at wet foam (g) & 262.00 & 270.00 & 282.00 & 293.00 \\
\hline Packing dry weight (g) & 91.00 & 95.00 & 97.00 & 101.00 \\
\hline \multicolumn{5}{|l|}{ Initial moisture content $(\mathrm{g})$} \\
\hline Total & 175.60 & 184.80 & 185.70 & 195.20 \\
\hline Instrument & 1.53 & 1.28 & 1.40 & 1.88 \\
\hline Initial $\mathrm{pH}$ & 6.87 & 6.92 & 6.83 & 6.83 \\
\hline Packing height $(\mathrm{cm})$ & 30.3 & 30.3 & 30.3 & 30.3 \\
\hline Packing volume (L) & 1.70 & 1.70 & 1.70 & 1.70 \\
\hline
\end{tabular}

dium was conducted at room temperature. The moisture content of the fixed bed was adjusted to approximately $65 \%$ for a variety of influent gas flow rates and toluene concentrations. Influent toluene concentrations and influent flow rates were chosen based on their range of conditions employed in the biofiltration experiments. The experiments to determine adsorption capacity of the filter medium were conducted by setting the syringe pump and influent airflow rate at the desired levels and measuring influent and effluent toluene concentrations over time until influent and effluent concentrations were equal. Mass of toluene adsorbed to the packing medium was then estimated by subtracting the mass of effluent toluene and the mass of toluene in the water of foam from the mass of influent toluene. Henry's law was used to calculate the concentration of toluene in the water phase (Henry's law constant $=0.00664 \mathrm{~atm}-\mathrm{m}^{3} / \mathrm{mol}$ ). The mass of toluene in the water phase was calculated by multiplying the concentration by the mass of water present in the wet foam.

\subsection{Biofilter Operation}

For the inoculation of microorganisms, activated sludge was obtained from the Shincheon municipal wastewater treatment plant in Daegu, Korea and the PU foam was submerged in the activated sludge (3 L) with aeration for 1 hour. Initial $\mathrm{pH}$ and moisture content were measured and listed in Table 2. The initial moisture content was measured by drying these foams at $65^{\circ} \mathrm{C}$ for 48 hours. To measure the initial $\mathrm{pH}$ of PU foam medium, $5.0 \mathrm{~g}$ of PU-PAC foam was mixed with $95 \mathrm{~g}$ of distilled water and the mixture was settled for 30 minutes.

For acclimation of the microorganisms, the influ- ent toluene concentration was kept at 15-25 ppm for the initial 10 days. After that, the influent toluene concentration was increased gradually by increasing the injection speed of the syringe pump. Total gas flow rate was kept at $2 \mathrm{~L} / \mathrm{min}$ for the 60 days of operation except $3 \mathrm{~L} / \mathrm{min}$ for the last 10 -day period. In the initial 10-day period (mode I), nutrient solution was added intermittently to the column reactors for the enhancement of microbial growth. For the next 40-day period (mode II-V) the drained water from the foam media was circulated through the column reactors and sometimes nutrient solution was added to prevent the packing media drying during the operation. In the last 10-day period (mode VI), only water was added in order to adjust moisture content of the packing materials. The nutrient solution was prepared by dissolving $8.2 \mathrm{~g}$ of $\mathrm{K}_{2} \mathrm{HPO}_{4}$, $21.4 \mathrm{~g}$ of $\mathrm{Na}_{2} \mathrm{HPO}_{4} \cdot 12 \mathrm{H}_{2} \mathrm{O}, 26.5 \mathrm{~g}$ of $\mathrm{KNO}_{3}, 17.7$ $\mathrm{g}$ of $\left(\mathrm{NH}_{4}\right)_{2} \mathrm{SO}_{4}, 1.8 \mathrm{~g}$ of $\mathrm{FeSO}_{4} \cdot 7 \mathrm{H}_{2} \mathrm{O}, 0.2 \mathrm{mg}$ of $\mathrm{MgSO}_{4} \cdot 7 \mathrm{H}_{2} \mathrm{O}, 0.9 \mathrm{mg}$ of $\mathrm{MnSO}_{4} \cdot 7 \mathrm{H}_{2} \mathrm{O}, 1.0 \mathrm{mg}$ of $\mathrm{NaMoO}_{4} \cdot 2 \mathrm{H}_{2} \mathrm{O}$ and $3.0 \mathrm{mg}$ of $\mathrm{CaCl}_{2}$ in $1 \mathrm{~L}$ of deionized water. ${ }^{7}$

During the experimental period, water loss was measured by gravity and recovered through sprinkling the nutrient solution and/or water on the top of the column. The experiment was carried out at room temperature of $20-25^{\circ} \mathrm{C}$. The influent and effluent toluene concentrations were measured using toluene gas detection tubes (GASTEC, model 122 and 122L, Japan). The detection limit of 122 and $122 \mathrm{~L}$ tube was $5 \mathrm{ppm}$ and $1 \mathrm{ppm}$, respectively. The pressure drop and the moisture content were measured by using water manometer and load cells. The $\mathrm{pH}$ of the drained water was measured using a Thermo Orion $\mathrm{pH}$ meter (model $720 \mathrm{~A}^{+}$). 


\subsection{Biodegradation Kinetic Analysis}

The toluene degradation kinetics was analyzed by the Michaelis-Menten equation developed for enzyme mediated reactions ${ }^{18-20)}$.

$$
-\frac{d C}{d Z}=\frac{V_{m} \cdot C}{K_{s}+C}\left(\frac{S_{a}}{F}\right) \cdot \alpha
$$

where $C=$ influent toluene concentration $\left(\mathrm{ppm}_{\mathrm{v}}\right)$, $Z$ = length of column $(\mathrm{m}), V_{m}=$ maximum removal rate ( $\mathrm{g}$ toluene $/ \mathrm{kg}$ dry material/day), $K_{s}=$ saturation constant (ppm), $S_{a}=$ cross-sectional area of column $\left(\mathrm{m}^{2}\right), F=$ total gas flow rate $\left(\mathrm{m}^{3} /\right.$ day $), \mathrm{L}=$ height of packed bed, and $\alpha=$ conversion coefficient ( $\mathrm{kg}$ dry material/g toluene)

$$
\alpha=\frac{22.4 \times\left(\frac{273+T}{T}\right) \times 10^{-6}}{M \times 1000} \times \frac{W}{V}
$$

where $T=$ temperature $\left({ }^{\circ} \mathrm{C}\right), W=$ dry weight of packing material $(\mathrm{kg}), V=$ volume of packing material $\left(\mathrm{m}^{3}\right), M=$ the molecular weight of toluene $(\mathrm{g} / \mathrm{mole})$

Integrating Eq. (1) under the condition of $C=C_{0}$ at $Z=0$ and $C=C_{\mathrm{e}}$ at $Z=\mathrm{L}$, we obtain ${ }^{182020}$ :

$$
\begin{aligned}
& \int_{C_{b}}^{C_{f}}\left(\frac{K_{s}}{V_{m}} \cdot \frac{1}{C}+\frac{1}{V_{m}}\right) d C=-\frac{S_{a} \cdot \alpha}{F} \int_{0}^{L} d Z \\
& \frac{K_{s}}{V_{m}}\left(\ln C_{0}-\ln C_{e}\right)+\frac{1}{V_{m}}\left(C_{0}-C_{e}\right)=\frac{S_{b} \cdot \alpha \cdot L}{F}
\end{aligned}
$$

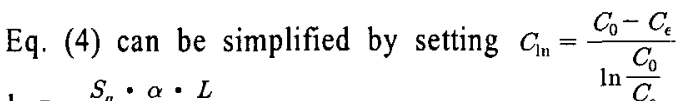
and $R=\frac{S_{n} \cdot \alpha \cdot L}{F \cdot \ln \frac{C_{0}}{C_{e}}}$ :

$$
R=\frac{K_{s}}{V_{m}}+\frac{1}{V_{m}} \cdot G_{\mathrm{n}}
$$

From the linear plot of $R$ vs. $C_{\mathrm{ln}}, V_{\mathrm{m}}$ and $K_{\mathrm{s}}$ were calculated from the intercept and slope of line, respectively.

\subsection{SEM Analysis}

At the end of the biofiltration experiment, PU cube samples (approximately $1 \mathrm{~cm} \times 1 \mathrm{~cm} \times 1 \mathrm{~cm}$ ) were taken from the filter bed media, washed twice with phosphate buffer $(\mathrm{pH}=7.4)$, washed with acetone solution $(30 \%)$ and then dried at $30^{\circ} \mathrm{C}$ for 2 hours. The samples were finally dried in a critical point dryer (Hitachi, HCD-2, Japan). Examination was carried out in a digital scanning electron microscope (Hitachi, S-570, Japan) using an accelerating voltage by $15 \mathrm{kV}$.

\section{Results and Discussion}

\subsection{Adsorption Experiment}

Fixed bed adsorption experiment was performed using a glass column to determine sorption capacity of the PU-PAC foam under dynamic conditions. For the fixed bed adsorption experiment, the influent toluene concentration $\left(\mathrm{C}_{0}\right)$ was maintained at 50 and $100 \mathrm{ppm}$, respectively and EBRT was $39-42$ seconds. Figures 2 and 3 present the results of adsorption experiments for the PU foams containing various adsorbents at the influent toluene concentration of 50 $\mathrm{ppm}$ and $100 \mathrm{ppm}$, respectively. The time to reach breakthrough was in the order of column I $>$ column II $>$ column III $>$ column IV mainly due to difference in PAC content.

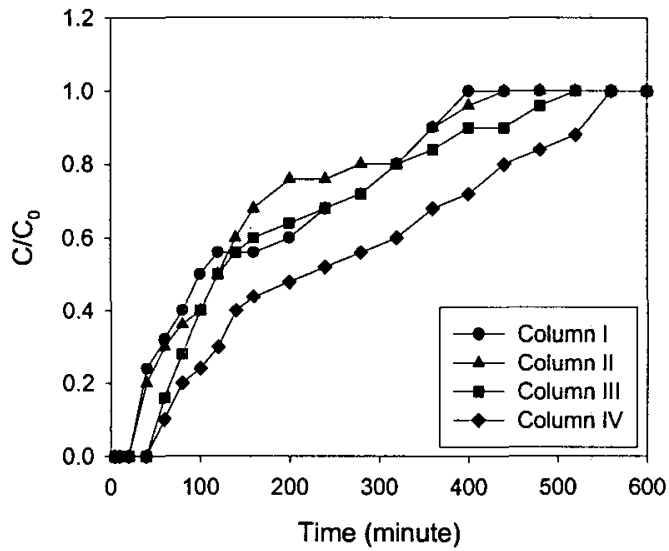

Fig. 2. Adsorption of toluene for PU-adsorbent foams. $\left(C_{0}\right.$ $=50 \mathrm{ppm}$ )

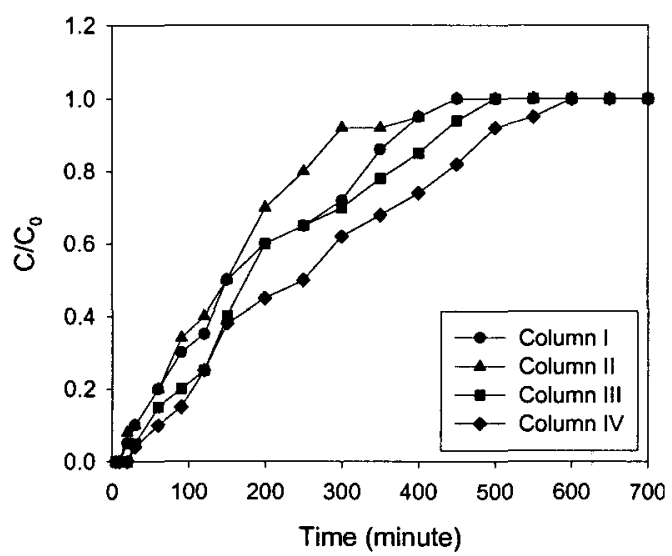

Fig. 3. Adsorption of toluene for PU-adsorbent foams. $\left(C_{0}\right.$ $=100 \mathrm{ppm}$ ) 
Biofiltration of Gaseous Toluene Using Activated Carbon Containing Polyurethane Foam Media

Table 3. Results of toluene adsorption experiment at $C_{0}=50 \mathrm{ppm}$ and $\mathrm{C}_{0}=100 \mathrm{ppm}$, respectively

\begin{tabular}{|c|c|c|c|c|c|}
\hline $\mathrm{C}_{0}(\mathrm{ppm})$ & Column & $\begin{array}{l}\text { Mass in effluent } \\
\text { (mg) }\end{array}$ & $\begin{array}{l}\text { Gas concentration } \\
\text { in the water* }(\mathrm{ppm})\end{array}$ & $\begin{array}{c}\text { Mass in water* } \\
(\mathrm{mg})\end{array}$ & $\begin{array}{l}\text { Mass adsorbed } \\
\text { in foam (mg) }\end{array}$ \\
\hline \multirow{4}{*}{50} & Column I & 960 & 0.47 & 0.54 & $3,039.5$ \\
\hline & Column II & 800 & 0.49 & 0.57 & $3,199.4$ \\
\hline & Column III & 960 & 0.51 & 0.57 & $5,039.4$ \\
\hline & Column IV & 600 & 0.55 & 0.63 & $5,399.4$ \\
\hline \multirow{4}{*}{100} & Column I & 600 & 1.10 & 1.25 & $5,398.7$ \\
\hline & Column II & 600 & 1.10 & 1.27 & $5,398.7$ \\
\hline & Column III & 480 & 1.13 & 1.27 & $5,518.7$ \\
\hline & Column IV & 300 & 1.16 & 1.32 & $5,698.7$ \\
\hline
\end{tabular}

${ }^{*}$ Calculated using Henry's law

Total toluene mass adsorbed in the PU-adsorbent foam was estimated and summarized in Table 3. When the influent toluene concentration was $50 \mathrm{ppm}$, $3,040,3,199,5,039$, and $5,399 \mathrm{mg}$ of toluene was adsorbed onto the column I ( $\mathrm{PAC}=4.95 \%)$, column II $(\mathrm{PAC}=7.09 \%)$, column III $(\mathrm{PAC}=8.97 \%)$ and column IV $(\mathrm{PAC}=13.52 \%)$, respectively. As expected, the adsorbed amount of toluene increased as PAC content in the PU foam increased. When the influent toluene concentration was $100 \mathrm{ppm}$, total adsorbed mass of toluene was $5,399 \mathrm{mg}$ in column I, $5,399 \mathrm{mg}$ in column II, $5,549 \mathrm{mg}$ in column III and $5,699 \mathrm{mg}$ in column IV, respectively. Total toluene mass adsorbed was increasing as the influent toluene concentration was increasing from $50 \mathrm{ppm}$ to 100 ppm. However, not much difference in adsorbed toluene mass was observed in between the columns. This was because the adsorption experiment was conducted under dynamic conditions.

\subsection{PU-PAC Foam Property}

Physicochemical properties of the prepared PU$A C$ foams are summarized in the Table 1 . The final content of PAC in the foam was determined by the difference between the mass of the cup after being dried in an oven at $65^{\circ} \mathrm{C}$ for 24 hours and the initial mass before use. The final contents of PAC in the PU foams were $4.95-13.52 \%$ of the total foam mass. Densities of dry and wet (moisture content $=65 \%$ ) PU foam were calculated by dividing mass by volume. Both dry and wet density of $P U$ foam increased as PAC content increased. Percent swelling in the vertical and horizontal direction was calculated by dividing the difference of wet and dry dimensions by the dry dimensions and multiplying by 100 . The void volume in the PU foam was measured using water displacement. The porosity of PU foam at $65 \%$ moisture content was approximately 0.77 for Foam A, 0.82 for Foam B, 0.77 for Foam C, and 0.78 for Foam D, respectively. In general the performance of biofilter would be highly dependent on the porosity of the PU foam. Therefore, the porosity of PU foam was determined to measure the void space for biomass growth and for passing airflow.

\subsection{Toluene Removal}

The four biofilter columns packed with PU-PAC foams were operated for 60 days in 6 different modes (mode I-VI) based on the total flow rate, influent toluene concentration, and supply of nutrient solution. The influent and effluent toluene concentrations in the biofilter systems are shown in Figure 4 . It is commonly observed that microorganisms exposed to a

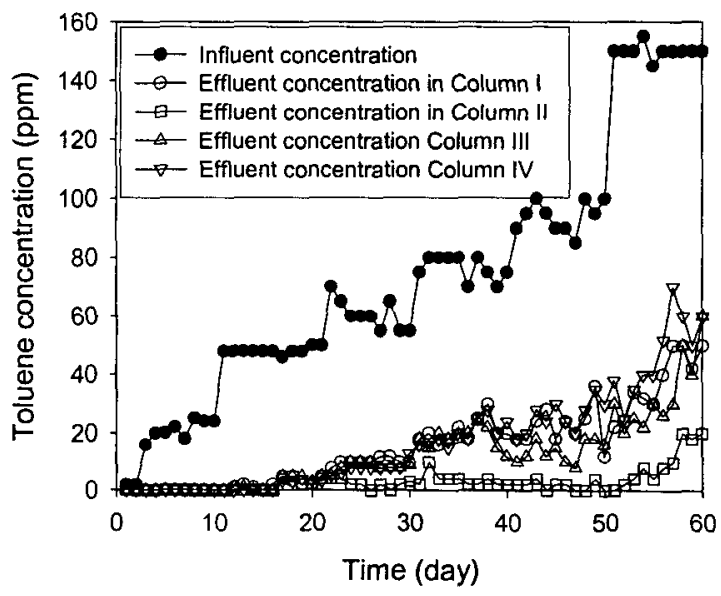

Fig. 4. Changes in toluene concentration over time. 
new substrate may require acclimation periods before they start active biodegradation. ${ }^{1,6)}$ In this study, thus, the data were obtained after a 10-day acclimation period. The total gas flow rate was $2 \mathrm{~L} / \mathrm{min}$ in the initial 50-day period (mode $\mathrm{I}-\mathrm{V}$ ) and $3 \mathrm{~L} / \mathrm{min}$ for the remaining period (mode VI).

At mode I (initial 10-day operation), the inlet toluene concentration was $15-20 \mathrm{ppm}$ and the outlet toluene was not detected in all columns. After mode $I$, the influent toluene concentration was increased gradually by increasing the syringe pump speed. At mode II, the influent toluene concentration gradually increased to $50 \mathrm{ppm}$ and the effluent toluene concentration was $0-5 \mathrm{ppm}$ in column I, II, and III and 0-4 $\mathrm{ppm}$ in column IV, respectively. At mode III, the effluent toluene concentration gradually increased as the influent toluene concentration increased to $55-70$ $\mathrm{ppm}$. The effluent toluene concentrations increased up to $5-12 \mathrm{ppm}$ in column I, $0-4 \mathrm{ppm}$ in column II, $5-10 \mathrm{ppm}$ in column III, and $3.13 \mathrm{ppm}$ in column IV, respectively. During the operation of mode I-III, column II showed the lowest effluent toluene concentration among the four tested columns.

From mode IV, the effluent toluene concentrations increased more rapidly as the influent toluene concentration increased up to $70-80 \mathrm{ppm}$. The effluent toluene concentrations was $18-30 \mathrm{ppm}$ in column I, 12-24 ppm in column III, and 15-28 ppm in column IV, respectively. However, much lower effluent concentration of 2-10 ppm was maintained in column II. At mode $\mathrm{V}$, the influent toluene concentration was further increased to $85-100 \mathrm{ppm}$. The effluent concentration was kept at $0.4 \mathrm{ppm}$ in column II whereas the effluent concentrations increased up to $12-36$ ppm in column I, 8-18 in column III, and 18-35 $\mathrm{ppm}$ in column IV, respectively. At mode VI, the toluene influent concentration was further increased to $150 \mathrm{ppm}$ and column II showed much lower effluent concentration $(0-20 \mathrm{ppm})$ than the other columns $(22-50 \mathrm{ppm}$ in column I, 22-60 ppm in column III, and 25-70 ppm in column IV, respectively).

Removal efficiency of pollutants is an important parameter influencing the degree of compliance of the control systems with emission regulations. The removal efficiency is defined as the percentage ratio of the difference between the influent and the effluent toluene concentration to the influent toluene

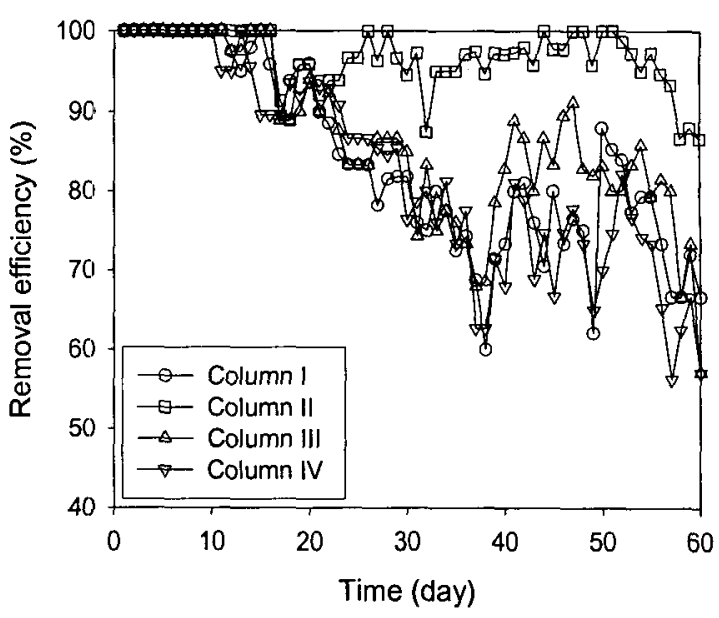

Fig. 5. Changes in toluene removal efficiency over time.

concentration. Figure 5 shows the toluene removal efficiency of biofilter columns packed with various PU-PAC foam media. Toluene removal efficiencies of the four biofilter columns decreased gradually as influent concentration increased. During the whole experimental period (from mode I to mode VI), the toluene removal efficiency in column II (86-100\%) was consistently higher than the other columns. In the last operation mode (mode VI, influent toluene concentration $=150 \mathrm{ppm}$ ), the removal efficiency decreased to $66-85 \%$ in column I, $57-85 \%$ in column III, and $56-82 \%$ in column VI, respectively. Although the removal efficiency decreased as the influent toluene concentration increased for all PU-PAC foam media, the removal efficiency in column II was consistently higher than the other columns. One possible explanation for the higher removal efficiency in column II is attributed to higher porosity of PU-PAC foam used in column II than the others (Table 1). In the most cases, a homogeneous filter bed with a porosity or void volume of 40 to $80 \%$ will ensure both gas plug flow and low pressure drop ${ }^{1)}$. In the biofiltration process, higher pollutant concentration can increase mass transfer rate from gas phase to liquid phase and then to the biofilm where the contaminants are biodegraded ${ }^{1,21)}$. It also provides sufficient substrate accessible for microbial growth. However, it is possible that influent toluene in the gas phase is not fully transferred into the liquid phase and the biofilm and thus the toluene may not be fully degraded by the biofilm when the influent toluene concentration is too high. This is the 


\section{Biofiltration of Gaseous Toluene Using Activated Carbon Containing Polyurethane Foam Media}

reason why the removal efficiency decreases as the influent toluene concentration increases. The mass transfer rate can be a limiting factor when the liquid phase is not saturated with the contaminant. The biodegradation rate can also be a limiting factor when the liquid phase is fully saturated with the contaminant ${ }^{19}$.

During the whole experimental period, $\mathrm{pH}$ variation of the drained water was monitored and showed at Figure 6. The $\mathrm{pH}$ of drained water decreased from 7.2 to 5.5 . This $\mathrm{pH}$ decrease is mainly due to the biological oxidation. That is to say, a toluene molecule loses an electron in an oxygen atom and carbon dioxide is produced as a result of biodegradation. The $\mathrm{pH}$ in a biofilter may change during operation and many of the contaminant biotransformations which occur in biofilters generate acids although a near-neutral $\mathrm{pH}(6$ to 8$)$ is required for the greatest spectrum of bacterial activity ${ }^{1)}$. Including buffering materials such as calcium carbonate in the medium can be an effective means for controlling a near-neutral $\mathrm{pH}$. In our study, column II showed nearer-neutral $\mathrm{pH}$ than the other columns without any buffering materials.

The pressure drop of column is related to the accumulation of biomass in the filter media. During the 60-day operation, pressure drop in all columns never exceed $3 \mathrm{~mm} \mathrm{H}_{2} \mathrm{O} / \mathrm{m}$ filter bed. The pressure drop observed in this study was much lower than the typical pressure drop of $25-37.5 \mathrm{~mm} \mathrm{H}_{2} \mathrm{O} / \mathrm{m}$ filter bed reported by Deshusses and Hamer. ${ }^{22)}$ Ergas et al. reported pressure drops of $100-600 \mathrm{~Pa} / \mathrm{m}$ at corresponding superficial air velocities through the biofilter

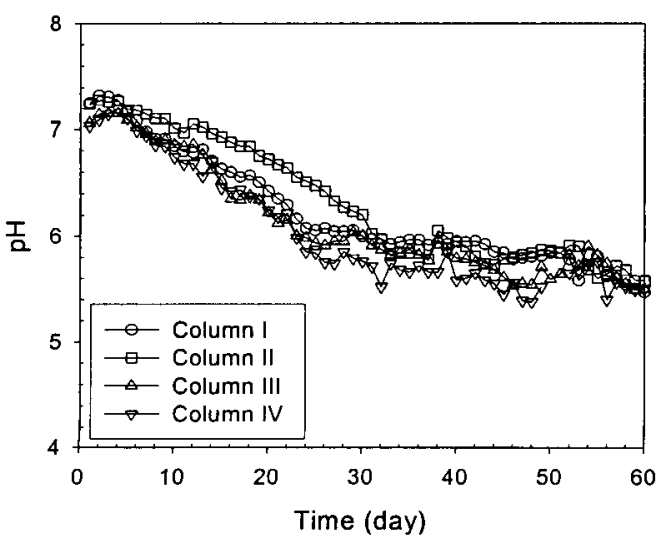

Fig. 6. Change in $\mathrm{pH}$ of the drained water over time. of $0.3-1.8 \mathrm{~m}^{3} / \mathrm{m}^{2} / \mathrm{min}^{5}$. These pressure drops were achieved by addition of perlite to the filter materials. Sorial et al. reported that as the toluene loading increased from 16.8 to $25.3 \mathrm{~kg} / \mathrm{m}^{3}$, pressure drop increased from 64 to $127 \mathrm{~mm} \mathrm{H}_{2} \mathrm{O} / \mathrm{m}$ using diatomite as packing material ${ }^{10)}$.

\subsection{Toluene Removal Capacity}

The appearance of continuous low removal capacity could be an indicator of poor environmental and/or operational conditions for resident microbial population $^{3)}$. Figure 7 presents the relationship between toluene removal capacity and loading rate. The solid line indicates that the removal capacity is equal to the toluene loading rate hence a $100 \%$ removal is obtained. The complete removal capacity was defined as the influent toluene was completely removed and thus no effluent concentration was observed, while the maximum removal capacity was defined as the value when the removal capacity leveled off ${ }^{19}$. The estimated values for maximum and complete removal capacity are listed in Table 4. On the basis of both packing weight and packing volume, both maximum and complete removal capacities were the highest in column II. In column II packed with PU-PAC foam ( $7.08 \%$ of PAC content), the maximum removal capacity would be much larger than $9.27 \mathrm{~g}$ toluene $/ \mathrm{kg}$ dry material/day if the toluene loading increased much higher than $9.46 \mathrm{~g}$ toluene/kg dry material/day. However, the other columns showed the maximum removal capacity of $6.13-7.36 \mathrm{~g}$ toluene $/ \mathrm{kg}$ dry material/day. Consequently, the column II showed better removal efficiency than the other columns.

\subsection{Biodegradation Kinetics}

To determine the biodegradation kinetic parameters for the biofiltration process, the values of $C_{\ln }$ and $R$ (Eq. 5) were calculated. The relationship between $C_{\text {ln }}$ and $R$ for various PU-PAC foams was shown in Figure $8 . C_{\text {ln }}$ and $R$ were linearly correlated for all PU-PAC foams $\left(\mathrm{R}^{2}>0.96\right)$. From the linear relationship between $C_{\mathrm{ln}}$ and $R$, the values of $V_{\mathrm{m}}$ and $K_{\mathrm{s}}$ were calculated from the slope and the intercept and listed in Table 5. Estimation of these parameters is useful for comparing the performance of biofilters packed with PU-PAC foams with different PAC contents. As listed in Table 5, the maximum removal rate $\left(V_{\mathrm{m}}\right)$ was $8.92,14.99,10.38$, and $7.48 \mathrm{~g}$ tol- 
Altangerel Amarsanaa, Won-Sik Shin, Jeong-Hak Choi and Sang-June Choi
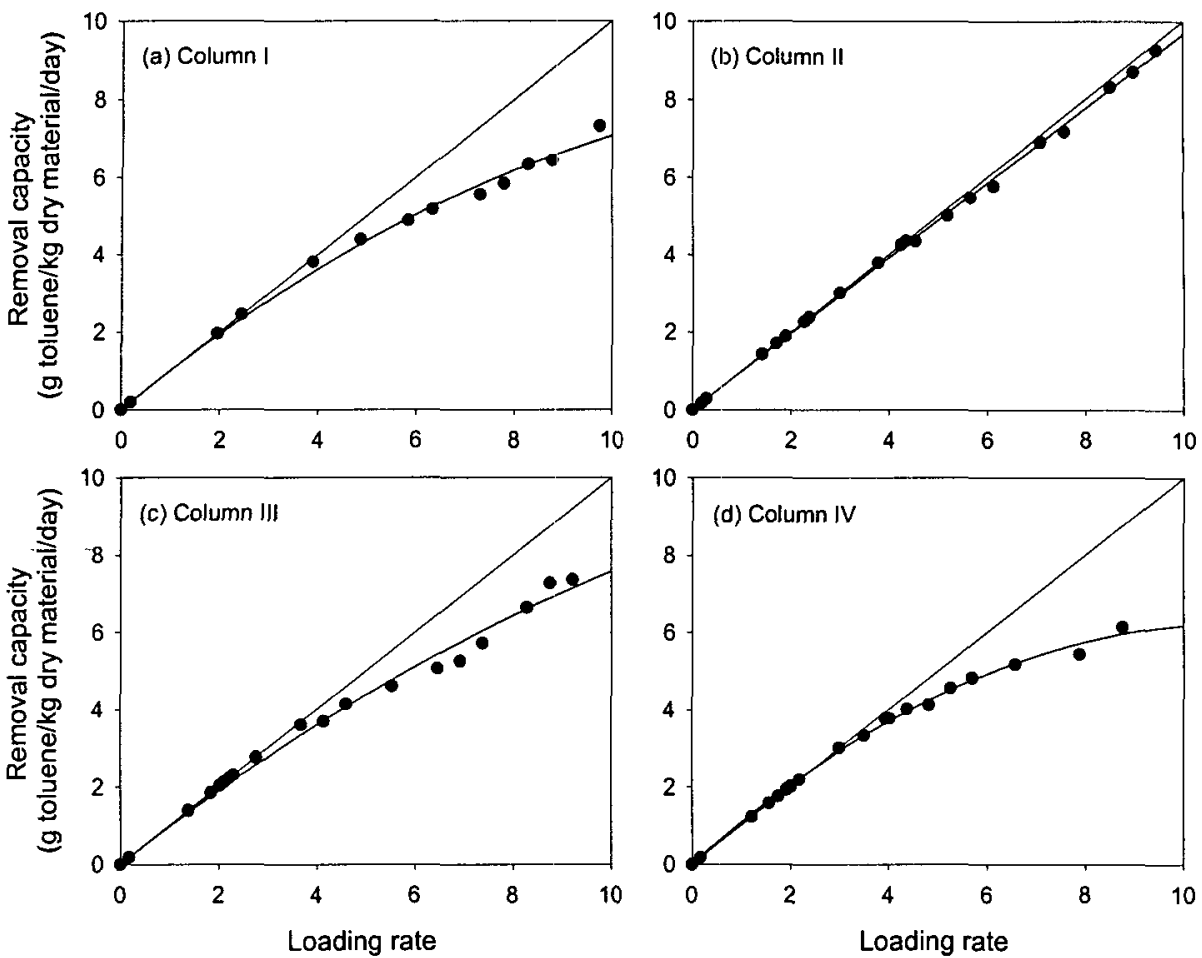

( $g$ toluene/kg dry material/day)

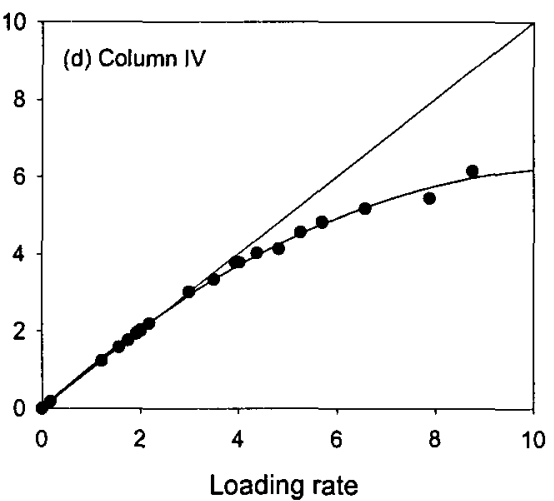

(g toluene/kg dry material/day)

Fig. 7. Relationship between toluene removal capacity and loading rate.

uene/kg dry material/day and the saturation constant $\left(K_{\mathrm{s}}\right)$ was $29.96,35.52,40.16$, and $26.06 \mathrm{ppm}$ for column I, column II, column III and column IV, respectively. Among the four columns, similar to the experimental result of maximum removal capacity, column II packed with PU-PAC foam containing
$7.08 \%$ of PAC had the highest values of the maximum removal rate $\left(V_{\mathrm{m}}=14.99 \mathrm{~g}\right.$ toluene $/ \mathrm{kg}$ dry material/day).

Generally, a physical process such as adsorption occurs prior to biological degradation in biofilm when influent concentrations are lower than the satu-

Table 4. Maximum and complete removal capacities of toluene for PU-PAC columns

\begin{tabular}{lccccc}
\hline & \multicolumn{2}{c}{ Maximum removal capacity } & \multicolumn{2}{c}{ Complete removal capacity } \\
\cline { 2 - 3 } \cline { 5 - 6 } & $\begin{array}{c}\mathrm{g} \text { toluene/ } \mathrm{kg} \text { dry } \\
\text { material/day }\end{array}$ & $\begin{array}{c}\mathrm{g} \text { toluene } / \mathrm{m}^{3} \mathrm{dry} \\
\text { material/day }\end{array}$ & & $\begin{array}{c}\mathrm{g} \text { toluene/ } \mathrm{kg} \text { dry } \\
\text { material/day }\end{array}$ & $\begin{array}{c}\mathrm{g} \text { toluene } / \mathrm{m}^{3} \mathrm{dry} \\
\mathrm{material} / \text { day }\end{array}$ \\
\hline Column I & 7.31 & 686.20 & 3.80 & 357.20 \\
Column II & 9.27 & 889.92 & 4.34 & 416.64 \\
Column III & 7.36 & 728.64 & 3.59 & 355.41 \\
Column IV & 6.13 & 662.04 & 3.32 & 358.56 \\
\hline
\end{tabular}

Table 5. Maximum removal rate and saturation constant for PU-PAC columns

\begin{tabular}{|c|c|c|c|}
\hline & \multicolumn{2}{|c|}{ Maximum removal rate $\left(V_{\mathrm{m}}\right)$} & Saturation constant $\left(K_{\mathrm{s}}, \mathrm{ppm}\right)$ \\
\hline Column I & $8.92^{a}$ & $838.48^{b}$ & 29.96 \\
\hline Column II & 14.99 & 1439.04 & 35.52 \\
\hline Column III & 10.38 & 1027.62 & 40.16 \\
\hline Column IV & 7.48 & 807.84 & 26.06 \\
\hline
\end{tabular}

Units: ${ }^{a} \mathrm{~g}$ toluene $/ \mathrm{kg}$ dry material/day and ${ }^{b} \mathrm{~g}$ toluene $/ \mathrm{m}^{3}$ dry material/day 
Biofiltration of Gaseous Toluene Using Activated Carbon Containing Polyurethane Foam Media
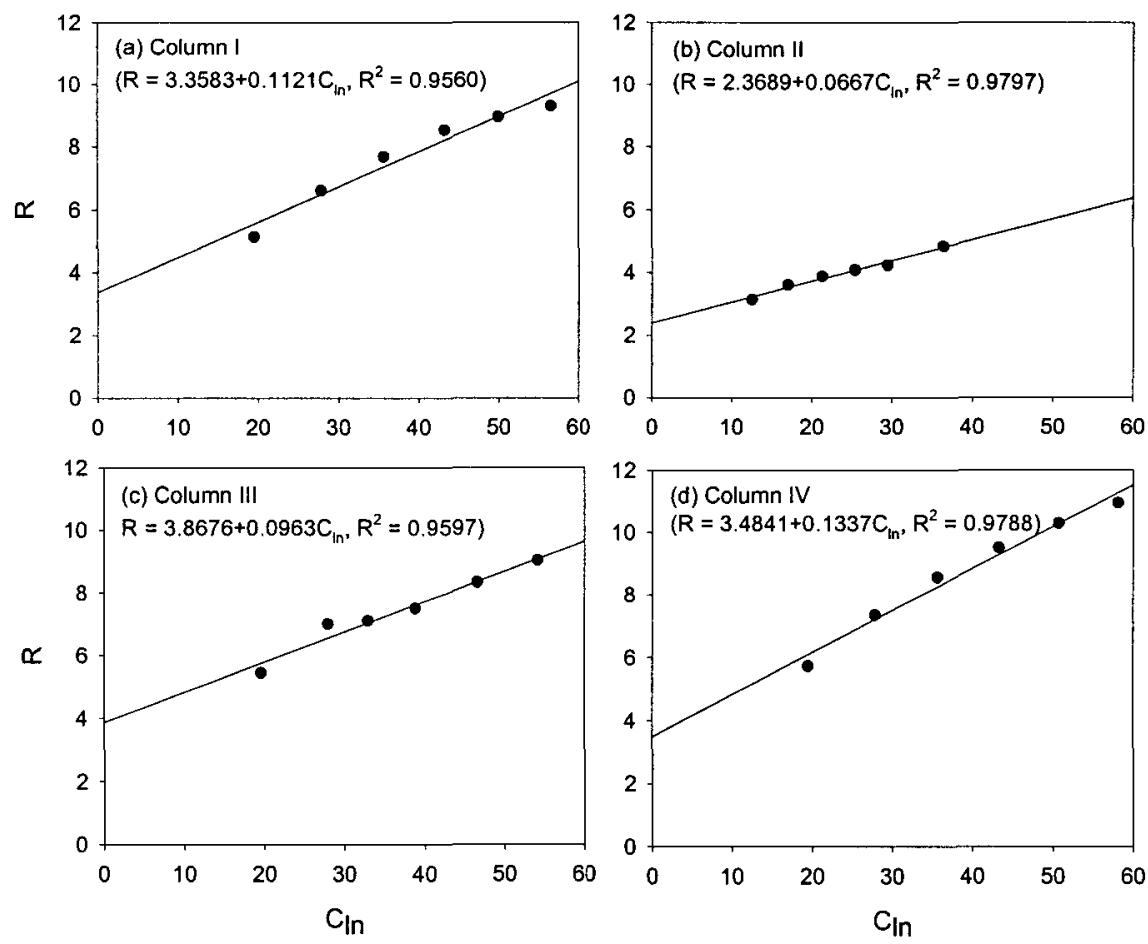

Fig. 8. Relationship between $R$ and $C_{l n}$ for all columns.

ration constants $\left(K_{\mathrm{s}}\right)$. Therefore the adsorption of toluene to the adsorbent containing in PU foam media may occur at early stage of the experiment. However, as the influent toluene concentration increased above the saturation constants $\left(K_{\mathrm{s}}\right)$, biodegradation rather than adsorption becomes a limiting factor of the biofiltration process. The biodegrdation kinetic parameters are useful for comparing the characteristics of biofilters with different packing materials. In this study, column II packed with PU foam with $7.08 \%$ of PAC content had the highest values of $V_{\mathrm{m}}$ and $K_{s}$. Whereas the column IV with the highest PAC content had the lowest values of $V_{\mathrm{m}}$ and $K_{\mathrm{s}}$. From these results, it was concluded that the PU foam structure and properties could be more critical factors in biofiltration rather than the PAC content in the PU foam.

The toluene removal rate determined by $V_{\mathrm{m}}$ and $K_{\mathrm{s}}$ using kinetic equation, Eq. (1) for columns was depicted in Figure 9. For all materials, the toluene removal rate steeply increased as influent toluene concentration increased up to $30-40 \mathrm{ppm}$. Above $30-40$ $\mathrm{ppm}$, the removal rate increased steadily and finally reached to a plateau. As listed in Table 5, the results

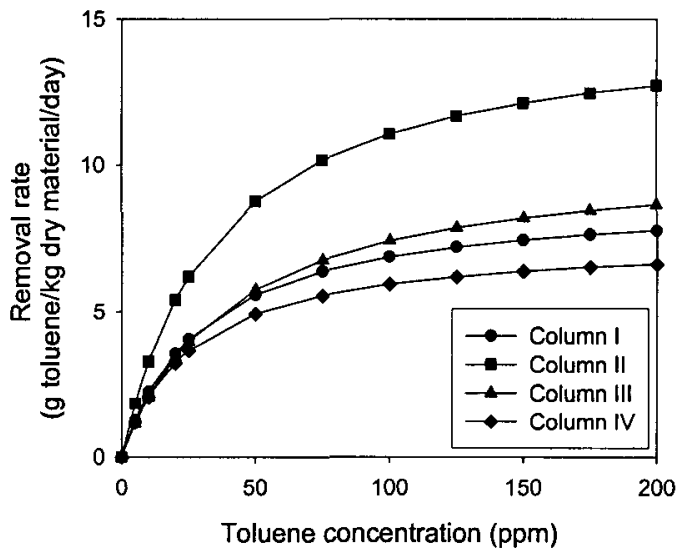

Fig. 9. Relationship between toluene removal rate and concentration.

of biodegradation kinetic analysis showed that the saturation constant $\left(K_{s}\right)$ was approximately $26-40$ $\mathrm{ppm}$. This indicates that mass transfer from gas phase to biofilm is rate-limiting factor and thus the toluene removal rate increases abruptly mainly by saturation at below saturation constant. In contrast, biodegradation becomes rate-limiting factor at concentration above the saturation constant and thus toluene removal rate increases steadily as toluene concentration 


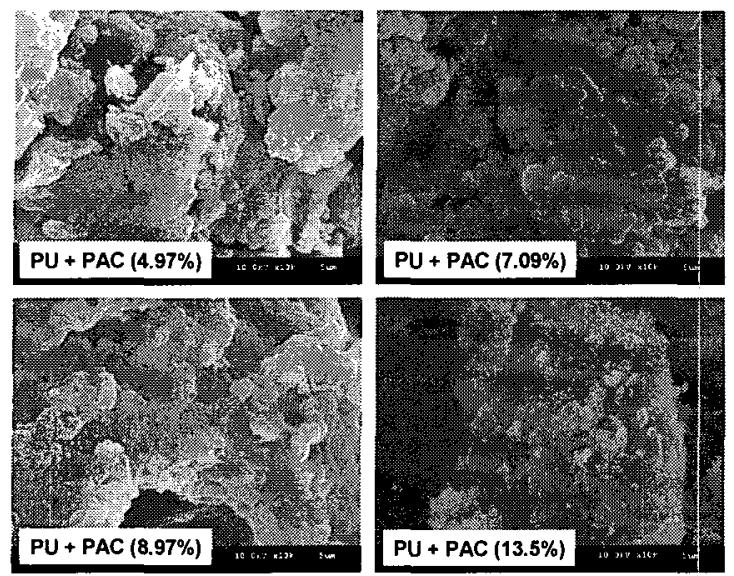

Fig. 10. SEM microphotographs of PU-PAC foams after biofiltration.

increases, finally reaching maximum removal rate. Toluene removal rate was in the order of column II $>$ column III $>$ column I $>$ column IV. The toluene removal rate in column II $>10 \mathrm{~g}$ toluene/dry material/day), was higher than those in other columns.

\subsection{Scanning Electron Microscopy}

At the end of biofiltration experiment, samples of the PU-PAC foam media were observed under scanning electron microscopy (SEM). Figure 8 shows the PU-PAC foam media with abundant growth of microorganisms after 60 days of the biofilter operation.

\section{Conclusions}

The following conclusions were obtained from results of this study:

1) For biofiltration experiment, the effluent toluene concentration increased as influent toluene concentration increased. However, the removal efficiency decreased gradually as influent toluene concentration increased.

2) For all PU-PAC foams, the toluene removal capacity increased as the loading rate increased, while the removal efficiency had an opposite trend. The biofilter packed with PU-PAC foam with $7.08 \%$ of PAC content showed higher toluene removal efficiency and had higher maximum and complete removal capacity than the others.

3) The results of biodegradation kinetic analysis showed that the maximum removal rate $\left(V_{\mathrm{m}}\right)$ in column II were higher than the other columns.
The results of kinetic analysis indicate that the biofiltration performance is more affected by PU foam structure and properties than the PAC content in the foam.

\section{References}

1) Devinny, J. S., M. A. Deshusses and T. S. Webster, 1999, Biofiltration for Air Pollution Control, CRC Press, Boca Raton, FL, USA, $299 \mathrm{pp}$.

2) Martinez, F. A., 2001, Polyurethane Foam based Packing Media for Biofilters Removing Volatile Organic Compounds from Contaminated Air, M.S. Thesis, Louisiana State University, Baton Rouge, LA, USA, 84pp.

3) Torkian, A., R. Dehghanzadeh and M. Hakimjavadi, 2003, Biodegradation of aromatic hydrocarbons in a compost biofilter, J. Chem. Technol. Biotechnol., 78, 795-801.

4) Moe, W. M. and R. L. Irvine, 2000, Polyurethane foam medium for biofiltration, Part II: Operation and Performance, J. Env. Eng., 126, 826-832.

5) Ergas, S. J., E. D. Schroeder, D. P. Y. Chang and R. L. Morton, 1995, Control of volatile organic compound emissions using a compost biofilter, Water Environ, Res., 67, 816-821.

6) Moe, W. M. and R. L. Irvine, 2001, Polyurethane foam based biofilter media for toluene removal, Wat. Sci. Technol., 43(11), 35-42.

7) Moe, W. M. and R. L. Irvine, 2001, Effect of nitrogen limitation on performance of toluene degrading biofilters during transient loading, Wat. Res., 35, 1407-1414.

8) Kinney, K. A., W. Wright, D. P. Chang and E. D. Schroeder, 1997, Biodegradation of vapor phase contaminants, In: Fundamentals and Applications of Bioremediation: Principles, 1, S. K. Sikdar and R. L. Irvine (eds.), Technomic Publishing, Inc., Lancaster, PA, USA, pp.601-630.

9) Ergas, S. J., E. D. Schroeder and D. P. Chang, 1992, Biodegradation technology for volatile organic compound removal from air streams, Phase I: Performance verification, Prepared for Research Division, California Air Resources Board, Final Report Under Contract No. AO-32-137.

10) Sorial, G. A., F. L. Smith, M. T. Suidan and P. Biswas, 1995, Evaluation of trickle bed biofilter 
media for toluene removal, J. Air \& Waste Manage. Assoc., 45, 801-810.

11) Holubar, P., C. Andorfer and R. Braun, 1995, Prevention of clogging in trickling filters for purification of hydrocarbon-contaminated waste air, Proc. of the 1995 Conference on Biofiltration, University of Southern California, D. S. Hodge and F. E. Reynolds, Jr., (eds.), 115-122.

12) Farmer, R. W., J. S. Chen, D. M. Kopchynski and W. J. Maier, 1995, Reactor switching: proposed biomass control strategy for the biofiltration process, In: Biological Unit Processes for Hazardous Waste Treatment, R. E. Hinchee, G. D. Sayles and R. S. Skeen (eds.), Battelle Press, 3, 243-248.

13) Severin, B. F., J. Shi, B. G. Cybul, L. M., Neilson and J. L. Furstenberg, 1995, High-rate low volume biofilters for industry, WEF: Industrial Wastes Technical Conference, Multimedia Pollution Control and Preventions, Pittsburgh, PA, USA, pp. 352.

14) Moe, W. M., R. L. Irvine and C. D. Montemagno, 1997, Preliminary investigation of polyurethane foam medium for use in vapor phase biofiltration, Proc. 199 CSCE-ASCE Env. Eng. Conf.: Protecting People and the Env., Edmonton, AB, Canada, S.J. Stanley and C.J.W. Ward (eds.), CSCE, Montreal, PQ, 1755-1766.

15) Moe, W. M. and R. L. Irvine, 2000, Polyurethane foam medium for biofiltration, Part I: Characterization, J. Env. Eng., 126, 815-825.

16) Szycher, M., 1999, Szycher's Handbook of Polyurethanes, CRC Press, Boca Raton, FL, USA, 696pp.
17) Lu, C., W. Chu and M. Lin, 2000, Removal of BTEX vapor from waste gases by a trickle bed biofilter, J. Air \& Waste Manage. Assoc., 50, 411-417.

18) Choi, J. H., Y. S. Jeong, Y. H. Kim, D. J. Joo, S. J. Choi, T. W. Ha, D. H. Lee and I. H. Park, 2003, Removal of ammonia by biofilters: A study with flow-modified system and kinetics, J. Air \& Waste Manage. Assoc., 53, 92-101.

19) Kim, N., M. Hirai and M. Shoda, 2000, Comparison of organic and inorganic packing materials in the removal of ammonia gas in biofilters, J. Hazard. Mater., 72, 77-90.

20) Yani, M., M. Hirai and M. Shoda, 1998, Removal kinetics of ammonia by peat biofilter seeded with night soil sludge, J. Ferment. Bioeng., 85, 502-506.

21) Liu, Y., Y. Sun, J. Chen, D. Xue and J. S. Chung, 2002, Simultaneous removal of ethyl acetate and toluene in air streams using compost-based biofilters, J. Hazard Mater., 95, 199. 213.

22) Deshusses, M. A. and G. Hamer, 1993, The removal of volatile ketone mixtures from air in biofilters, Bioproc. Biosyst. Eng., 9, 141-146.

23) Abumaizar, R. J., W. Kocher and E. H. Smith, 1998, Biofiltration of BTEX contaminated air streams using compost-activated carbon filter media, J. Hazard. Mater., 60, 111-126.

24) Delhomenie, M., L. Bibeau, N. Bredin, S. Roy, S. Broussau, R. Brzezinski, J. L. Kugelmass and M. Heitz, 2002, Biofiltration of air contaminated with toluene on a compost-based bed, Adv. Environ. Res., 6, 239-254. 